\title{
THE SURGERY OF RHEUMATIC DISEASE
}

\author{
By John Bastow, M.D., F.R.C.S.
}

The proper attitude for a surgeon confronted with a case of rheumatic disease should be one of humility. He can offer palliation but not cure. If he attempts to remake a joint by performing an arthroplasty, then the new joint will be a poor thing compared with a natural joint and will certainly not stand up to the wear and tear of an active life so well. If he confesses failure and eradicates the joint, performing an arthrodesis, then the patient will gain stability and freedom from pain only at the expense of a stiff and awkward limb. In the words of the sceptic, he is converting one kind of cripple into another. It behoves him to make doubly sure that the transition is worth while before undertaking the requisite surgery.

There are certain well tried and tested operations that have given worthwhile results in properly selected cases, and the young surgeon would be well advised to begin by confining his efforts to these, as the results of experimental surgery on the arthritic are likely to be very disappointing.

In the choice of operation for a particular patient, there are many factors to be considered.

I. First and foremost, the individual concerned and his attitude to his disability.

2. Is he fit enough to stand a major operation ?

3 . Will he co-operate in the necessary aftertreatment?

4. If the operation succeeds in increasing his range of activity, will his heart stand up to the extra strain involved ?

5. Is the prime need for a stable jointespecially in the lower limb ?

6 . Is mobility the aim, especially in the upper limb ?

7. What is the risk of a secondary flare-up of arthritis if an attempt is to be made to form a new joint ?

8. What effect is the procedure likely to have on neighbouring joints ?

9. How will the patient tolerate any postoperative recumbency that may be required?

Io. What are the alternatives, i.e. if the operation is not done, what is the probable course of the disease likely to be?
Such questions and many others should be $\vec{\omega}$ considered before a decision is made to operate on a patient with rheumatic disease. These 8 patients should not be regarded as guinea pigs, fit subjects for a whole range of surgical $\omega$ experiments.

\section{Osteoarthritis}

In osteoarthritis, when pain and interference with function reaches a stage where surgery can justifiably be considered, then arthrodesis is still the sheet anchor of the surgeon's repertoire. The joints that lend themselves most readily to this procedure of stabilization are:

In the lower limb:

I. The hip-especially in young or middle age adults who want to lead an active life. The method ज़ of Watson-Jones (1938), Brittain (1942)-pre ferably by Foley's posterior approach to safeguard the sciatic nerve (1949) and the central dislocation method of Charnley (1952) all give excellent results. It is better to fix the joint in a position of a few degrees of adduction and external rotation, and $\propto$ about $20^{\circ}$ of flexion if a natural gait is to be $\overline{\overline{0}}$ attained, and the patient is to be able to sit with any ease.

2. The knee. This joint lends itself readily to arthrodesis and Charnley's method (1948) with the use of compression pins certainly facilitates early union and lessens the risk of the bone ends slipping out of position during post-operative splintage. Opinions differ sharply as to the optimum position for arthrodesis. Some prefer a position just short of full extension which retains height and gives a good gait, while others prefer $\frac{D}{0}$ about $30^{\circ}$ of flexion, particularly in women, to allow for ease of sitting. The needs of each $N$ individual case should be studied in this respect.

3. The ankle. This joint should be fixed in a few degrees of equinus and there are many $\omega$ acceptable methods such as the use of a tibial graft

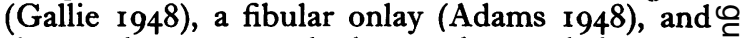
the apple-corer method as advocated by $\mathrm{Mr}$. Kenneth Pridie (personal communication).

This latter consists of a straight medial approach and turning down the medial malleolus by an 


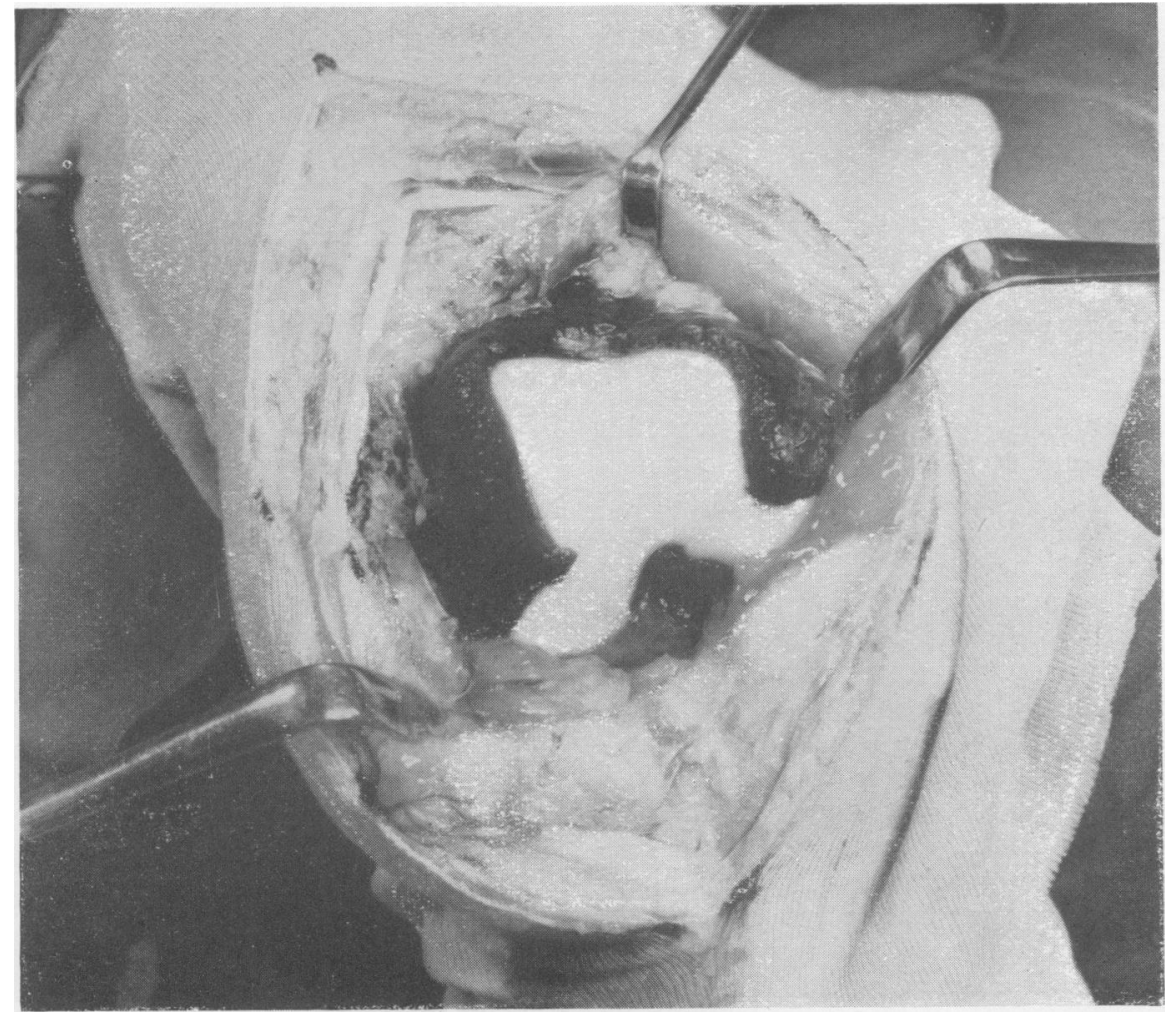

FIG. I.-Synovectomy-articular surfaces exposed at operation showing early marginal erosion of the femoral condyles, still compatible with a good result.

oblique cut with an osteotome to expose the inner side of the joint. A cylindrical core of bone including the joint surfaces is then taken horizontally across the joint by the use of a Forcner auger bit. The resulting bone and cartilage debris is then collected and packed firmly into the cavity across the joint and the internal malleolus refixed in position.

4. The tarsal joints. The triple arthrodesis of Naughton Dunn (1928) and that of Lambrinudi, as described by Hart (1940), are sound procedures, but should be undertaken with caution in patients of middle age and over. They are best tolerated by the adolescent or young adult.

5. The metatarsophalangeal joint of the great toe lends itself well to an arthrodesis in a foot where a Keller's operation (Campbell I949) would throw too much strain on an inefficient anterior metatarsal arch. It should be fixed in about $15^{\circ}$ of dorsiflexion and it is wise to use some form of internal fixation such as a screw or Kirschner wire, or a sliding bone-graft to ensure bony union.

6. The interphalangeal joints of the toes may require stabilizing and both Young's spike operation (1938) and the method of Sir Robert Jones modified by transfixion with a Kirschner wire, as๊ advocated by Campbell (I949) give good results.

In the upper limb:

I. The shoulder occasionally requires arthrodesis in an active person. Bone union is not always easy to obtain and some form of internal fixation is often helpful, as in the methods of Watson 3 Jones (1933) and Charnley (195I). The bestoposition is one of $45^{\circ}$ abduction, $45^{\circ}$ forward 3 . flexion and $45^{\circ}$ external rotation.

2. The elbow may require arthrodesis in manual worker and should be fixed at an angleo to suit the individual's occupation, often at about $120^{\circ}$. Mobility should be retained in the superior radio-ulnar joint by excising the head of the radius if necessary.

3. The wrist. Arthrodesis of this joint at abouto $20^{\circ}$ of dorsifiexion is a very satisfactory operation $\mathrm{N}_{\mathrm{w}}$ There are many techniques with or without bone? graft. It is usually necessary to excise the lowero end of the ulna to retain the ability to rotate the forearm.

4. The thumb. Arthrodesis of a painful and unstable carpo-metacarpal joint is a satisfactory 


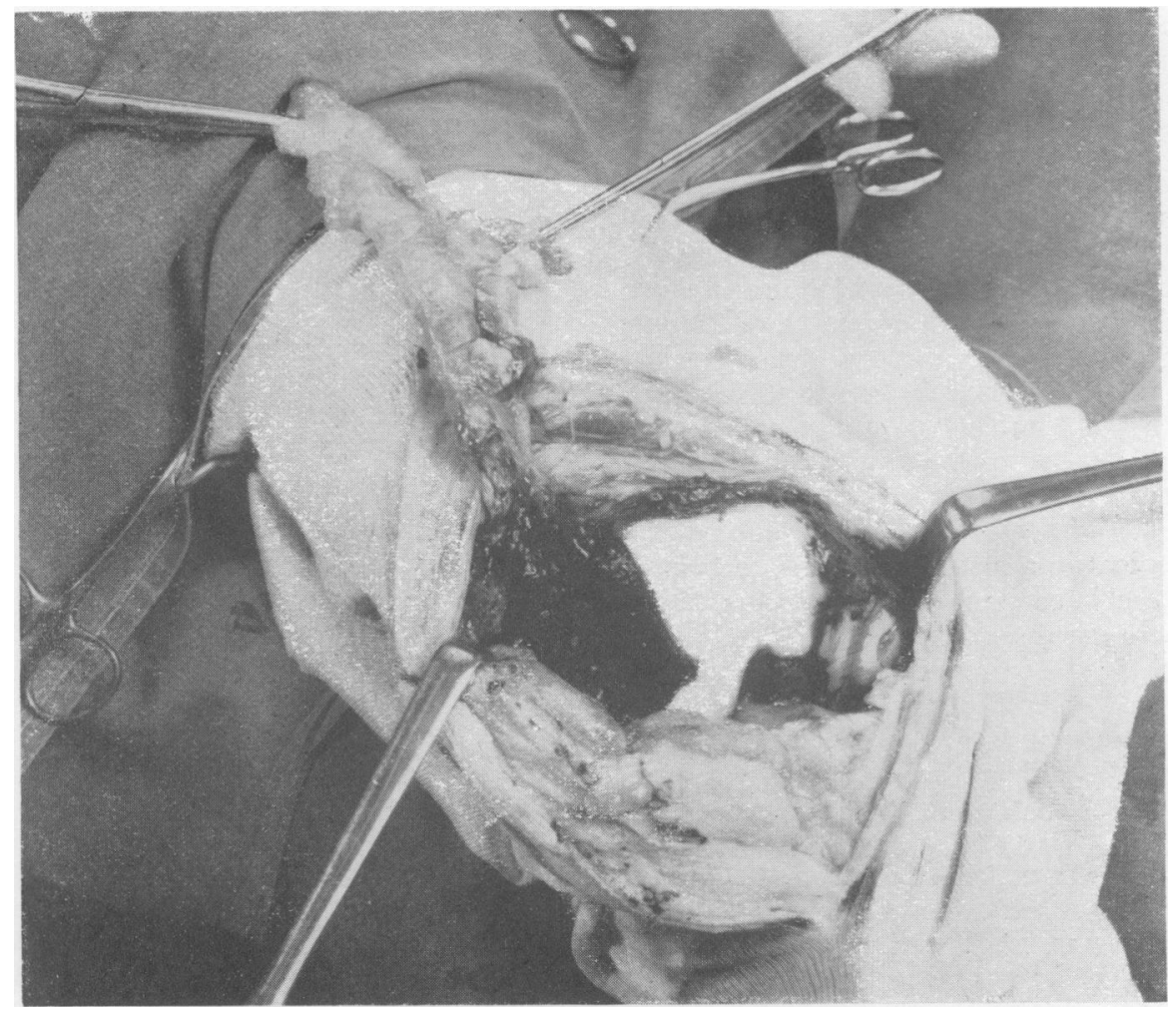

operation but relief of pain in older people can be obtained more quickly by excision of the trapezium.

5. The fingers. Occasionally an unstable interphalangeal joint calls for arthrodesis in slight flexion. A transfixion wire is helpful in securing fixation to ensure bone union.

6. The spine. Fusion of a localized osteoarthritic joint in the spine, especially following injury or an intervertebral lesion is a satisfactory operation by any of the recognised techniques. I have found the $\mathrm{H}$-graft either taken from the ilium or from the bone-bank simple and satisfactory.

\section{Measures Designed to Retain Foint Mobility.}

The simpler are the pseudarthroses where a mobile joint is ensured by a wide removal of bone at the expense of subsequent stability. The common examples are:

I. Keller's operation for the great toe.

2. Excision of either the upper or lower end of the ulna to ensure free pronation and supination of the forearm.

3. Excision of either the outer or the inner end of the clavicle for arthritic changes in the acromioclavicular or sterno-clavicular joints respectively.
4. Excision of the metacarpal head for an advanced arthritis of the knuckle-joint of a finger.

5. Excision of the trapezium for osteoarthritis of the metacarpocarpal joint of the thumb.

6. Excision of the head and neck of the femur (Girdlestone 1945), especially valuable in the elderly patient where relief of pain is demanded and retention of mobility is a great advantage.

All are useful procedures that can be relied on to relieve pain and produce a good range of movement at the expense of some loss of strength. Keller's operation, however, demands a very careful régime of post-operative exercises to restore active plantar flexion of the joint in order to secure a successful result, and should not be undertaken if the metatarsal arch is already badly splayed and causing symptoms of metatarsalgia.

Foint Debridement (Magnuson 194I) and (Iserlin 1950).

This procedure is sometimes useful in osteoarthritis of the knee, particularly where the arthritis is largely confined to the patellofemoral compartment and the patient has good muscular control of the joint. In a successful case, it can 
be relied on to give a stable knee and a range of movement up to $90^{\circ}$.

\section{Osteotomy}

The supreme example of the successful use of this procedure is MacMurray's operation (1935) for osteoarthritis of the hip. If performed on a suitable case with a shallow acetabulum, a short femoral neck, sufficient joint mobility remaining to allow free adduction and no gross flexion contracture, then it can be relied on to relieve pain and give a useful, stable hip at the expense of about 50 per cent. loss of the total range of movement of the joint. Many surgeons are now using some form of internal fixation to prevent having to put the patient in a plaster spica and so risking stiffness of the knee joint in the post-operative phase. Where it is essential to retain a good range of movement, the procedure advocated by Batchelor (1948) of excision of the head and neck of the femur, followed three weeks later by an osteotomy of the Schanz type (Gaenslen 1935) certainly improves the stability of the excised hip.

\section{Arthroplasty}

The hip and the elbow are the joints which respond best to this procedure. The whole question of arthroplasty of the hip has recently been exhaustively reviewed by Dr. Shepherd (r954) on behalf of the British Orthopaedic Association. Her conclusions are that the majority of cup arthroplasties deteriorate after four years and of Judet operations after two years. A smaller percentage of cases showed good results and no tendency to deterioration. It was not yet possible, however, to answer the question 'why do some arthroplasties succeed while others fail ?', or even to give the patient a confident and reliable prognosis.

Judet's arthroplasty (1952) and the techniques using prostheses to replace the femoral head have been widely used in late years. In spite of initially favourable impressions there is no doubt that the late results of these techniques have proved very disappointing in a large majority of cases.

The acrylic resin at first used in the manufacture of these prostheses does not stand up to wear and often either breaks or erodes within I 8 months or so. Nylon prostheses are apt to cause local irritation of the tissues and should not be used. Metallic prostheses stand up to use well but bone absorption is apt to occur where the metal is joined to the femoral neck, and painful symptoms tend to recur within two or three years.

On the whole, however, my impression is that the cup arthroplasty seems to stand up to the wear and tear of active use better than the Jude prosthesis does in the long run (Devas 1954). $\cong$

The whole question of the choice of operation in chronic arthritis of the hip has been recentl产 reviewed by Coltart (1953) and, though I feel ho regards the Judet prosthesis with more enthusiasno that the late results of this operation warrant, hes general conclusions are indubitably sound.

\section{Rheumatoid Arthritis}

The peculiar problem in the surgery of rheu $\overrightarrow{0}$ matoid arthritis is the difficulty of foretelling with any accuracy the subsequent course of the disease The progress of a case is characterised by remis sions and relapses so that the moment whe surgical intervention becomes advisable is difficult to assess. The failure of cortisone and ACTH t $\overrightarrow{D_{3}}$ put a definite end to the rheumatoid disease doeso however, invest the surgeon with a certaig responsibility in a limited field.

If a local focus of rheumatoid disease does nof respond to rest and conservative measures, then at stage may be reached when the synovial proliferap tion progresses to complete destruction of the articular surfaces and intra-articular ligaments The same sort of thing may occur in rheumatoi inflammation of the synovial lining of tendon. sheaths or bursae. A timely surgical excision 0 年 the diseased synovia before irreparable damage been done may give the affected joint or tendon new lease of life. The tissues are quite capable of forming a new synovial lining by metaplasia, give the necessary stimulus by early movement of the part, and this procedure is especially valuable in

I. Synovectomy of the knee. The place of synovectomy of the knee in rheumatoid arthritis is carefully reviewed in a paper by $\mathrm{Mr}$. Peter London soon to be published in the British fourna of Bone and Foint Surgery. His conclusion, witt which I am in full agreement, is that in properl selected cases, this operation is a useful example of ' surgical salvage.' In order that this operation. shall have a reasonable chance of success, it essential that it is undertaken while the disease is largely confined to the synovial membrane. Whe the articular cartilage has been invaded to the extent of showing an irregular and narrowed join space on the X-ray film, and when the ligamentss have been involved so that the joint has marked lateral or anteroposterior instability, then the time has already passed when a successful result can b. expected from synovectomy (Bastow 1947). The subsequent progress of the case will depend largely on the patient's general condition. If the general health remains good, then the new synoviaf lining will probably continue to function well and the arthritis will remain locally arrested. If there is a general relapse of rheumatoid disease, then 
is by no means improbable that the new synovium will be affected by the same process and the joint condition may ' flare up' again. In cases where rheumatoid arthritis is complicated by the presence of flexion contracture, Preston (1953) has advocated an operative procedure that consists essentially of a flexor release combined with debridement of the joint and tightening of the extensor muscles. This procedure, like most operations in rheumatoid arthritis that aim at restoration of function, demands great co-operation on the part of the patient and full supportive therapy by means of ACTH or cortisone.

2. Rheumatoid involvement of bursae, especiially those behind the knee (Kersley 1954).

3. Rheumatoid involvement of the tendon sheaths of the fingers (Ansell and Bywaters 1953).

\section{Arthrodesis}

Rheumatoid joints lend themselves readily to arthrodesis as the bones are vascular and there is often a natural tendency to ankylosis. The procedure is especially valuable in cases with painful joint deformities as it is possible to correct the deformity as well as fuse the joint by the same operation. The knee, the ankle, the mid-tarsal, the sub-astragaloid and the wrist joints are the sites where arthrodesis is most often required in rheumatoid arthritis.

\section{Pseudarthrosis}

The knuckle joints of the fingers, where the metacarpal heads are excised, and the elbow, where a wide gap is left between the bony surfaces by excision of the upper ends of the radius and ulna and the articular condyles of the humerus, are the most suitable sites for this procedure. In such procedures, it is essential that the affected joint should have adequate post-operative splintage to allow healing without displacement of the bone ends. A plaster slab and bandage is adequate until the wound is healed. Later, some form of ' lively splintage' is helpful in steadying the new joint while muscular control is regained.

\section{Arthroplasty}

The hip is the only joint which lends itself to this operation in rheumatoid disease. A Vitallium cup arthroplasty is usually the best to employ as the decalcified bones do not tolerate the Judet and other type of prosthesis well in the long run. Results are often satisfactory from the patient's point of view for relief of pain and disappointing from the surgeon's aspect as the range of movement is usually poor.

Other operative procedures sometimes necessary in rheumatoid disease are:
I. Joint lavage, when the joint cavity is distended with fibrinous exudate which cannot be aspirated through a needle.

2. Tenotomy, especially of the tendo-achilles for drop-foot and of the adductor longus tendon for adduction contracture of the hip.

3. Amputation of the toes for uncontrollable deformity.

4. Excision of metatarsal heads for painful plantar callosities.

It must be remembered, however, that prevention is better than cure, and the timely application of rest plasters or plastic splints during the acute phases of the disease will often render surgery unnecessary. Flexion contractures of the knee can often be dealt with by serial manipulations and corrective plasters without recourse to operation being required.

\section{Gout}

Surgical intervention is sometimes required for removal of troublesome tophi but, as a rule, surgery is best avoided in this condition. Tissues widely infiltrated with deposits of sodium biurate seldom heal well and any surgical assault is apt to precipitate an acute attack of gout in a susceptible subject.

\section{Ankylosing Spondylitis}

Surgery in this disease should be chiefly confined to the correction of gross deformity, such as flexion contractures of the hips, knees and spine.

Osteotomy of the spine (Law 1952) should only be undertaken in cases where exceptionally good $\mathbb{\perp}$ nursing care can be given to the patient, and is $\overrightarrow{\vec{F}}$ a procedure not without risk, even in expert hands.

Deformity of the hips can be dealt with by osteotomy or by a pseudarthrosis combined with osteotomy of the type described by Batchelor (1948). Flexion contracture of the knees usually requires an arthrodesis (if the deformity is of long standing).

Ankylosis of the temporo-mandibular joint demands resection of the condyles of the mandible. If a bilateral operation is performed, great care 0 must be taken to prevent the tongue from slipping back and asphyxiating the patient during the first few days after operation (Law 1952).

To sum up, the surgery of rheumatic disease $N$ demands a cautious approach on the part of the $N$ surgeon, and there is no general rule suitable $\underset{\omega}{N}$ for all cases. Each case must be considered on $\sigma$ its merits and it cannot be too strongly emphasized that the attitude of the individual patient to his disease is a much more important factor in the $\stackrel{D}{\rightarrow}$ selection of cases for operation than the state of the actual joint concerned. 


\section{BIBLIOGRAPHY}

ADAMS, J. C. (1948), 'Arthrodesis of the Ankle Joint,' F. Bone E' $¥ t$. Surg., $30 \mathrm{~B}, 3,506$.

ANSELL, B. M., and BYWATERS, E. G. L. (1953), 'Finger Contractures Due to Tendon Lesions,' Ann. Rheum. Dis., $12,4,283$.

BASTOW, J. (1947), ' Surgery of the Rheumatoid Diseases,' Postgrad. med. $\mathcal{F} ., 23,325$.

BATCHELOR, J. S. (1948), Ibid., 24, 24 I.

BRITTAIN, H. A. (1942), 'Architectural Principles in Arthrodesis,' E. \& S. Livingstone,' Edinburgh.

CAMPBELL, W. C. (1949), 'Campbell's Operative Orthopaedics,' vol. 3, 1532 .

CHARNLEY, J. C. (1948), 'Positive Pressure in Arthrodesis of the Knee Joint, $\mathcal{F}$. Bone $\mathscr{E}^{\mathfrak{f}} \mathfrak{f}$ t. Surg., $3 \circ \mathrm{B}, 3,478$.

CHARNLEY, J. C. (195I), 'Compression Arthrodesis of the Ankle and Shoulder,' Ibid., $33 \mathrm{~B}, 2,180$.

CHARNLEY, J. C. (1952), ' New Operation for Osteoarthritis of Hip Joint,' Ibid., 34A, 4, 1003.

COLTART, W. D. (r953), 'Choice of Operation in Chronic Arthritis of the Hip,' Ann. Rheum. Dis., 12, 3.

DEVAS, M. B. (1954), 'Arthroplasty of the Hip;' $\mathcal{~}$. Bone $\mathfrak{F}^{\circ} \mathfrak{f t}$. Surg., 36B, 4, 561.

FOLEY, W. B. (1949), 'Ischio-Femoral Arthrodesis of the Hip by Posterior Open Approach,' Ibid., 31 B, 2, 222.

GAENSLEN, F. J. (1935), 'The Schanz Sub-trochanteric Osteotomy for Irreducible Dislocation of Hip,' Ibid., I7A, I, 76.
GALLIE, W. E. (1948), 'Arthrodesis of the Ankle Joint,' Ibid. $3 \circ \mathrm{OB}, 4,619$.

GIRDLESTONE, G. R. (1945), Proc. Roy. Soc. Med., 38, 363.

HART, V. L. (1940), 'Lambrinudi Operation for Drop-Foot, F. Bone Eீ $\mathscr{f}$ t. Surg., 22, 4, 937. ISERLIN, B. (1950), 'Joint Debridement for Osteoarthritis of the
Knee,' Ibid., 32B, 3, 302.

JUDET, R. (1952), 'Arthroplasty of the Hip,' Ibid., 34B, I, 153.

JUDET, R., and JUDET, J. (1952), 'Technique and Resultof with the Acrylic Femoral Head Prosthesis,' Ibid., 34B, 2, 173.

KERSLEY, G. D., et al. (1954), 'Degenerative Rheumatoide Changes,' Ibid., 36B, 2, 238 .

LAW, W. A. (1952), 'Surgical Treatment of Rheumatic Diseases, $\underline{D}$ Ibid., 34B, 2, 222.

MACMURRAY, T. P. (1935), Brit. F. Surg., 22, 716.

MAGNUSON, P. B. (194I), 'Joint Debridement: Surgical Treat $\overrightarrow{0}$ ment of Degenerative Arthritis,' Surg., Gynec., Obstet., 73, 1. .'

NAUGHTON, DUNN (1928), ' Arthrodesis of the Tarsus,' Oxford University Press, p. 395 .

PRESTON, R. L. (1953), Ann. Rheum. Dis., 12, 290.

SHEPHERD, M. M. (1954), 'A Review of 650 Hip Arthroplasteg

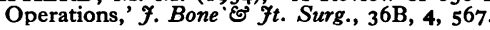

WATSON-JONES, R. (1933), 'Extra-articular Arthrodesis of Shoulder,' Ibid., 15, 862 .

WATSON-JONES, R. (1938), 'Arthrodesis of Hip,' $\mathcal{F}$. Amer med. Ass., $110,278$.

YOUNG, C. S. (1938), 'An Operation for the Correction of Hammer-Toe and Claw-Toe,' $\mathcal{F}$. Bone $\mathcal{F}^{\prime} \mathcal{F}$ t. Surg., 20, 3, 715

\section{NOTICE OF SPECIAL INTEREST TO SUBSCRIBERS:} "WHY NOT HAVE YOUR COPIES OF THIS
JOURNAL BOUND INTO YEARLY VOLUMES?"

\begin{abstract}
Arrangements have now been made to have the twelve monthly issues fully bound in dark green pin head cloth, lettered in gilt on spine with name of Journal, Volume Number and year, complete with index at front, 17s. 6d. per Volume, post free. A limited number of out of print journals are available to bind into volumes and make your library complece. Price on application giving details of issues required to complete back volumes.
\end{abstract}

THE FELlOWSHIP OF POSTGRADUATE MEDICINE 60 PORTLAND PLACE, LONDON, W.I

\section{WHY NOT HAVE YOUR JOURNALS BOUND?}

\section{Books Received}

The Editorial Board acknowledge with thanks receipt of the following iolumes. $\quad A$ selection from these will be made for review.

'The Pathogenesis of Poliomyelitis.' By Harold K. Faber, M.D. Pp. xvi + I57, with 16 illustrations. Oxford: Blackwell Scientific Publications. 1955. 36s.

' Corneal Grafts.' Edited by B. W. Rycroft, O.B.E., M.D., D.O.M.S., F.R.C.S. Pp. xii +285 . London: Butterworth \& Co., Ltd. 1955. 57s. 6d.

'The Cytology and Life-History of Bacteria.' By K. A. Bisset, D.Sc. Second edition. Pp. xii + r64, with 68 illustrations. Edinburgh: E. \& S. Livingstone Ltd. 1955. $25 \mathrm{~s}$.

' Neurochemistry.' Edited by K. A. C. Elliot, M.Sc., PH.D., Sc.D., Irvine H. Page, M.D., and
J. H. Quastel, D.Sc., PH.D., F.R.C.S., F.R.S.? with 32 contributors. Pp. xii +900 , illustrated Oxford: Blackwell Scientific Publications. I 955 을. $£ 7$.

'A Manuel of Psychiatry.' By K. ·R. Stall worthy, M.B., CH.B., Diploma Psychologicab Medicine. Third edition. Pp. 324. Christchurch N. M. Peryer Ltd. I 955 . 3os.

' Surgical Physiology of the Adrenal Cortex.' Bo James D. Hardy, M.S. (Chem.), M.D., F.A.C.S Pp. xxi + rgr, with 34 illustrations. Oxford Blackwell Scientific Publications. I $955.42 \mathrm{~s}$.

'Materia Medica.' Edited by J. K. W. Ferguson? 